Int. J. Electrochem. Sci., 14 (2019) 3509 - 3523

\title{
Corrosion Inhibition of Aluminum using Nonionic Surfactant Compounds with a Six Membered Heterocyclic Ring in 1.0M HCl Solution
}

\author{
F. H. Al-abdali ${ }^{1}$, M. Abdallah ${ }^{1,2, *}, R$. El-Sayed $^{1,2}$ \\ ${ }^{1}$ Chemistry Department, Faculty of Applied Sciences, Umm Al-Qura University, Makkah, Saudi \\ Arabia \\ ${ }^{2}$ Chemistry Dept., Faculty of Science, Benha University, Benha, Egypt \\ *E-mail: metwally555@yahoo.com
}

doi: $10.20964 / 2019.04 .59$

Received: 9 December 2018 / Accepted: 14 January 2019 / Published: 10 March 2019

The inhibiting vigor of a novel synthetic two nonionic surfactant (NS) compounds containing heterocyclic six membered ring moiety toward the corrosion of pure aluminum (Al) in $1.0 \mathrm{MHCl}$ solutions was inspected. Electrochemical techniques like galvanstatic polarization, electrochemical impedance spectroscopy and chemical technique such as weight loss, thermometric were utilized in this study. The NS compounds were identified by IR and 1HNMR spectra. The inhibition efficiency (IE \%) obtained from the four various techniques proved that the compounds performed as a good inhibitor for the corrosion of Al. The inhibition was explained by adsorption of NS compounds on the surface of Al. The IE \% values surge by increasing the concentration of NS compounds. The adsorption obeys Freundlich isotherm. . The activated thermodynamic parameters were computed and assessed

Keywords: Nonionic surfactant, Adsorption; corrosion inhibitors; Interfaces

\section{$\underline{\text { FULL TEXT }}$}

(C) 2019 The Authors. Published by ESG (www.electrochemsci.org). This article is an open access article distributed under the terms and conditions of the Creative Commons Attribution license (http://creativecommons.org/licenses/by/4.0/). 